\title{
Using Bayes' nomogram to help interpret odds ratios
}

\section{Introduction}

In certain scenarios, the odds ratio (OR) provides an unbiased estimate of the rate ratio in case control studies. ${ }^{1}$ However, the $\mathrm{OR}$ is also frequently used to estimate the risk ratio (relative risk) (RR) of an outcome in the presence of a risk factor. The degree of error in this estimate is frequently small, but can sometimes be substantial. The OR as an estimate of the RR always overestimates the effect of the exposure (results in an estimate further away from 1). The degree of divergence between the OR and the RR depends on the size of the OR and the probability of the outcome of interest (table) ${ }^{2-4}$ Given the value of the baseline risk and the estimate of the OR, the RR can be estimated by the use of a formula. ${ }^{35}$ However, the formula may be inconvenient and cumbersome for readers and users of epidemiological information. A nomogram is a graphical calculator that is a useful and convenient way to perform common calculations without the need to remember formulae. The use of the Bayes' nomogram $^{6}$ has simplified the use of diagnostic test information $^{7-8}$ and is now frequently used by physicians who may be unaware of the formula involved in the conversion. In this editorial, we show that the Bayes' nomogram, typically associated with likelihood ratios, can also be used to calculate the RR given the OR and the baseline risk.

\section{Method}

Our method uses 2 steps to convert from OR to RR, given a baseline risk. The first step uses Bayes' nomogram (figure). ${ }^{6}$ Using a straight edge on the nomogram, line up the baseline probability of an event on axis $\mathrm{A}$, with the OR on axis $\mathrm{B}$, and read off the postexposure probability on axis C. The postexposure probability divided by the baseline probability then yields the RR. Thus, with available information on the OR from epidemiological studies and the baseline risk, Bayes' nomogram calculates the postexposure risk in the presence of the risk factor. Knowledge of the postexposure risk also allows easy and accurate calculation of the absolute risk difference and the number needed to treat $(\mathrm{NNT})^{9}$ or the number needed to harm $(\mathrm{NNH}) .^{10}$

We present 2 examples to show the use of Bayes' nomogram to calculate postexposure probability, RR, absolute risk difference, and NNH.

Degree of divergence between odds ratios (ORs) and relative risks (RRs)*

\begin{tabular}{lllll}
\multirow{2}{*}{$\begin{array}{c}\text { Baseline } \\
\text { risk }\end{array}$} & $\mathbf{0 . 5}$ & $\mathbf{0 . 7 5}$ & $\mathbf{2}$ & 4 \\
\cline { 2 - 5 } $\mathbf{5 \%}$ & 0.49 & 0.74 & 2.11 & 4.75 \\
\hline $\mathbf{1 0} \%$ & 0.47 & 0.73 & 2.25 & 6.0 \\
\hline $\mathbf{2 0} \%$ & 0.44 & 0.70 & 2.67 & 16.0 \\
\hline $\mathbf{5 0} \%$ & 0.33 & 0.60 & NA & NA \\
\hline $\mathbf{7 0} \%$ & 0.23 & 0.47 & NA & NA \\
\hline
\end{tabular}

${ }^{*} \mathrm{NA}=$ not available (ie, not calculable)

The table lists the ORs corresponding to various RRs and baseline risks. Notice that as the baseline risk increases, and as the RR is further from 1 , the degree of divergence between the OR and the RR increases. Regardless of the magnitude of the RR, the OR is always further from 1 than the RR.

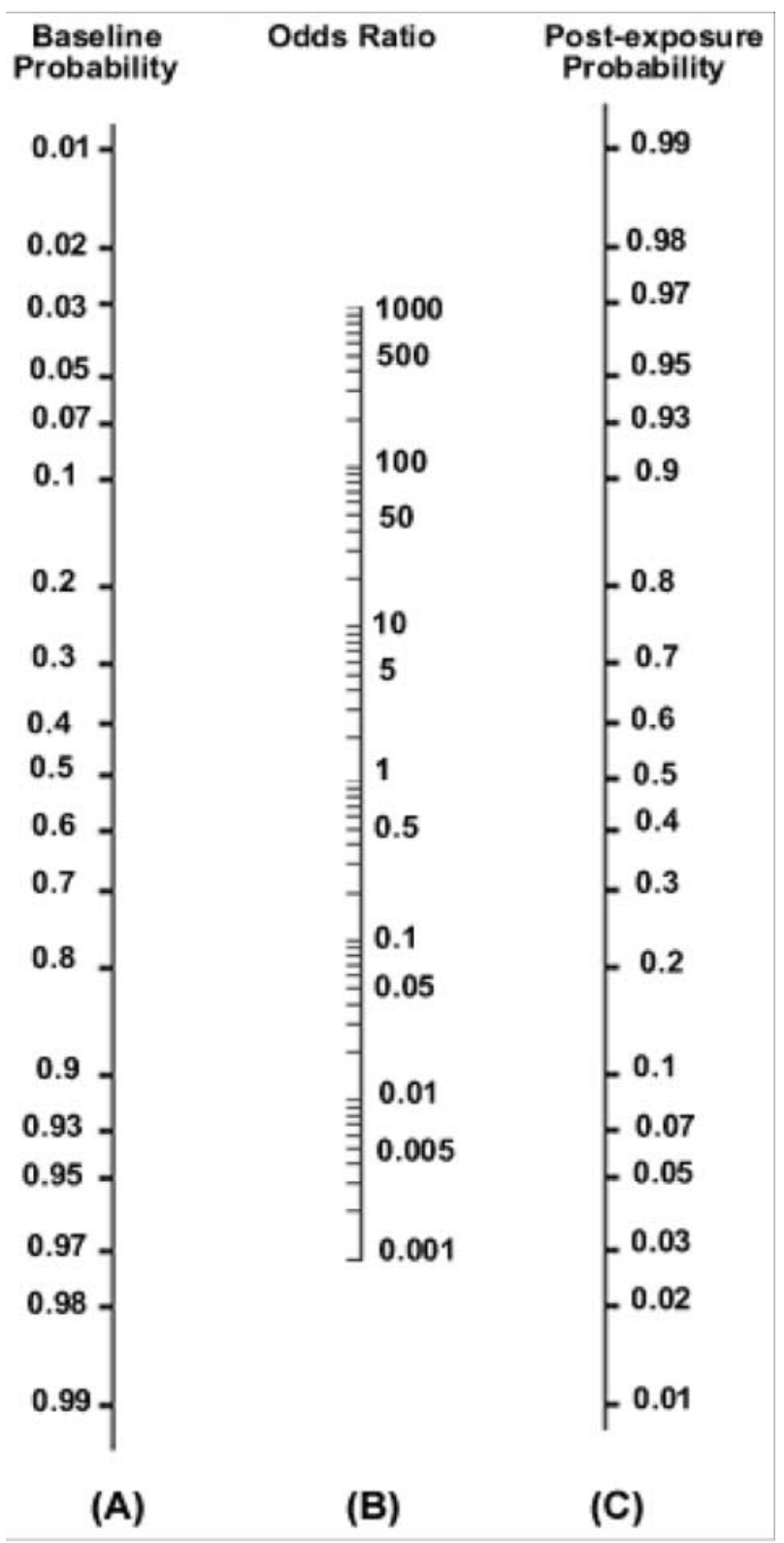

Nomogram to calculate postexposure probability given estimates of the odds ratio and baseline probability. This nomogram is equivalent to the Bayes' nomogram, but with different labels.

\section{EXAMPLE 1}

We are interested in estimating the risk for precipitating heart failure in an older man who has started taking nonsteroidal anti-inflammatory drugs (NSAIDs) for arthritis. Our search reveals a recent case control study ${ }^{11}$ suggesting an OR of 10.5 for developing heart failure associated with the use of NSAIDs by patients with a history of heart disease. To apply this information, we need to estimate our patient's baseline risk of heart failure. To do this, we use the equations derived by Kannel et al based on the Framingham database. ${ }^{12}$ Using the example 
given in that article of the 60 year old man with documented coronary disease who had a vital capacity of 2.51 , systolic blood pressure of $160 \mathrm{~mm} \mathrm{Hg}$, heart rate of 85 beats/min, and evidence of left ventricular hypertrophy on electrocardiogram and cardiomegaly on chest radiogram, this patient's 4 year risk of heart failure is $34 \%$. His 1 year risk is thus approximately $8.5 \%$. Using Bayes' nomogram (figure), we anchor a straight edge at 0.085 (baseline risk) on axis A and direct it through axis $\mathrm{B}$ at 10.5 (OR). The postexposure risk can be read off axis $\mathrm{C}$ as 0.49 , or a $49 \%$ chance of developing heart failure over 1 year after starting NSAIDs. The RR is then estimated by dividing the post-test probability, $49 \%$, by the pretest probability, $8.5 \%$, to get the RR of 5.8 (not an RR of 10.5 as some would misinterpret the OR). The absolute risk difference is $0.49-0.085=0.405$. The NNH is the reciprocal of the absolute risk difference of 0.405 , which is approximately 2.5. Thus, 5 such patients exposed to NSAIDs for a year would be expected to result in 2 new cases of heart failure.

\section{EXAMPLE 2}

A meta-analysis compared endoscopic ligation with sclerotherapy for the treatment of esophageal variceal bleeding. ${ }^{13}$ The overall rebleeding risk with sclerotherapy in the 7 included studies was $47 \%$; the OR was 0.52 (95\% CI 0.37 to 0.74$)$ in favour of ligation therapy. Although it might be tempting to interpret this as a $48 \%$ relative risk reduction (RRR), this is not accurate. Using Bayes' nomogram and anchoring the straight edge at 0.47 (baseline risk) on axis $A$ and 0.52 on axis $B(O R)$, we read 0.32 on axis $\mathrm{C}$, which is the probability of rebleeding with ligation (postexposure risk). To determine the RR associated with ligation compared with sclerotherapy, we divide 0.32 by 0.47 , giving an answer of 0.68 . This means that the RR is 0.68 and the RRR is $32 \%(1-0.68)$, not the $48 \%$ we would erroneously get if we equated the OR and RR without regard for the baseline risk and magnitude of the OR.

\section{Discussion}

ORs are frequently interpreted as RRs. Although the 2 are often very close, if the baseline risk is $>10-20 \%$ and the magnitude of the OR is far from 1, the divergence can be substantial. In these cases, we have shown how a Bayes' nomogram can be used to conveniently calculate more accurate estimates of the RRs. Please note, however, that since the nomogram axes are on the logarithmic scale, interpolation requires some care. Numbers greater than a given mark on the scale will be further away than would be predicted by using a linear scale. Given the fact that the likelihood ratio is a form of OR, and indeed that the positive likelihood ratio divided by the negative likelihood ratio gives the OR, it is not surprising that the nomogram should be suitable for this purpose. However, in our experience with teaching evidence-based medicine, it is an application of Bayes' nomogram that is not commonly known or used.

JOHN PAGE, MBBS, MSC Harvard University School of Public Health Boston, Massachusetts, USA JOHN ATTIA, MD, PHD, FRCPC University of Newcastle Newcastle, New South Wales, Australia

1 Rothman KJ, Greenland S. Modern epidemiology. Second edition. Philadelphia: Lippincott-Raven, 1998.

Davies HT, Crombie IK, Tavakoli M. When can odds ratios mislead? BMJ 1998;316:989-91.

3 Zhang J, Yu KF. What's the relative risk? A method of correcting the odds ratio in cohort studies of common outcomes. JAMA 1998;280:1690-1.

Sinclair JC, Bracken MB. Clinically useful measures of treatment effect in binary analyses of randomized trials. J Clin Epidemiol 1994;47:881-9.

5 McNutt LA, Wu C, Xue X, et al. Estimating the relative risk in cohort studies and clinical trials of common outcomes. Am J Epidemiol (157:940-3.

6 Fagan TJ. Letter: Nomogram for Bayes theorem. $N$ Engl J Med

7 Fletcher RH, Fletcher SW, Wagner EH. Clinical epidemiology: the essentials. Baltimore: Williams \& Wilkins, 1996.

8 Sackett DL, Haynes RB, Guyatt GH, et al. Clinical epidemiology: a basic science for clinical medicine. Second edition. Boston: Little, Brown, 1991.

9 Laupacis A, Sackett DL, Roberts RS. An assessment of clinically useful measures of the consequences of treatment. N Engl J Med 1988;318:1728-33.

10 Bjerre LM, LeLorier J. Expressing the magnitude of adverse effects in case-control studies: "the number of patients needed to be treated for one additional patient to be harmed." BMJ 2000;320:503-6.

11 Page J, Henry D. Consumption of NSAIDs and the development of congestive heart failure in elderly patients: an underrecognized public health problem. Arch Intern Med 2000;160:777-84

12 Kannel WB, D'Agostino RB, Silbershatz H, et al. Profile for estimating risk of heart failure. Arch Intern Med 1999;159:1197-204.

13 Laine L, Cook D. Endoscopic ligation compared with sclerotherapy for treatment of esophageal variceal bleeding. A meta-analysis. Ann Intern Med 1995;123:280-7.

www.evidence-basedmedicine.com 


\section{BECOME A SENTINEL READER}

The Health Information Research Unit at McMaster University, which prepares Evidence-Based Medicine, is recruiting frontline clinicians to help define the best research to support evidence-based clinical care and develop a "next generation" information service, exactly tailored to the interests of practicing doctors.

Our objective is to help physicians keep up to date with information that is truly relevant to the care of their own patients.

If you are an MD who has completed formal training and are in clinical practice at least part-time in internal medicine or its subspecialties or general practice/family medicine, then you qualify to participate.

As a Sentinel Reader:

- We'll send you hot-off-the-press articles that apply to your discipline(s), identified by a hand-search of over 100 journals, and that have been checked for scientific merit.

- You will rate the article on two scales, one for newsworthiness and another for relevance.

- The most pertinent articles will be abstracted in ACP Journal $C l u b$ and Evidence-Based Medicine and eventually incorporated into a new online service.

For your contribution:

- Earn CME credits (North America) - you will earn 1 CME credit for every 4 articles read and rated in our system (based on usual reading times to date).
- Stellar Articles - we will show you articles that you and your colleagues rated as 6 or more, on a scale of 7 , in your discipline(s).

- We'll collate your ratings with at least two other colleagues in your discipline and use your ratings to build an evidencebased information system for family physicians and internists.

MORE: McMaster Online Rating of Evidence

For more information on joining us as a Sentinel Reader: Please e-mail more@mcmaster.ca

How to cite material from Evidence-Based Medicine

Citation of material from the Notebook

Milne R, Hicks N. Evidence-based purchasing [EBM Note]. Evidence-Based Medicine 1996 May-Jun;1:101-2.

Citation for material taken from a structured abstract, written without attribution by a staff member

Antihypertensive drugs decrease mortality, coronary events, and stroke in elderly persons [abstract]. Evidence-Based Medicine 1996 May-Jun;4:105. Abstract of: Pearce KA, Furberg CD, Rushing J. Does antihypertensive treatment of the elderly prevent cardiovascular events or prolong life? A meta-analysis of hypertension treatment trials. Arch Fam Med 1995;4:943-50.

Citation for material taken from a commentary to an article

Olds D. Commentary on "Home visiting programmes reduce childhood injury" Evidence-Based Medicine 1996 May-Jun;4:112.

Comment on: Roberts I, Kramer MS, Suissa S. Does home visiting prevent childhood injury? A systematic review of randomised controlled trials. BMJ 1996;312:29-33.

\section{Journals reviewed for this issue*}

Acta Obstet Gynecol Scand
Age Ageing
Am J Cardiol
Am J Med
Am J Obstet Gynecol
Am J Psychiatry
Am J Public Health
Am J Respir Crit Care Med
Ann Emerg Med
Ann Intern Med
Ann Surg
Arch Dis Child
Arch Gen Psychiatry
Arch Intern Med
Arch Neurol

Age Ageing

Am J Cardio

Am J Psychiatry

Am J Public Health

Ann Emerg Med

Ann Intern Med

Ann Surg

Arch Intern Med

Arch Pediatr Adolesc Med

Arch Surg

Arthritis Rheum

BJOG

BMJ

Br J Gen Pract

Br J Psychiatry

BrJ Surg

CMAJ

Chest

Circulation

Cochrane Library

Crit Care Med

Diabetes Care

Gastroenterology
Gut

Heart

Hypertension

JAMA

J Am Coll Cardiol

J Am Coll Surg

J Am Geriatr Soc

J Clin Epidemiol

J Fam Pract

J Gen Intern Med

J Infect Dis

J Intern Med

J Neurol Neurosurg Psychiatry

J Pediatr
J Vasc Surg

Lancet

Med Care

Med J Aust

N Engl J Med

Neurology

Obstet Gynecol

Pain

Pediatrics

Rheumatology

Spine

Stroke

Surgery

Thorax

*Approximately 60 additional journals are reviewed. This list is available on request. 